\title{
Author Correction: Infralimbic cortex is required for learning alternatives to prelimbic promoted associations through reciprocal connectivity
}

\author{
Arghya Mukherjee (i) ${ }^{1} \&$ Pico Caroni (i) ${ }^{1}$
}

Correction to: Nature Communications https://doi.org/10.1038/s41467-018-05318-x, published online 13 July 2018.

The original version of this Article contained an error in the Acknowledgements, which incorrectly omitted from the end the following: 'This project has received funding from the European Research Council (ERC) under the European Union's Horizon 2020 research and innovation programme (MemoryDynamics - grant agreement No 694086).' This has been corrected in both the PDF and HTML versions of the Article.

Published online: 12 July 2019

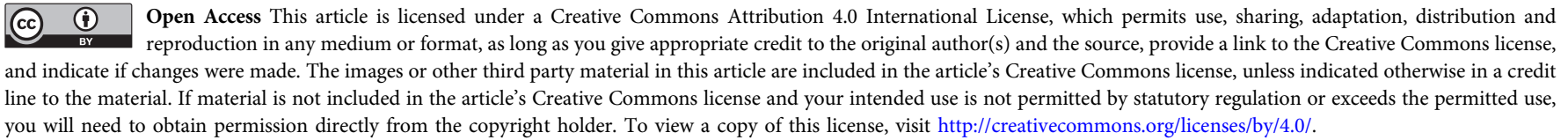

(C) The Author(s) 2019

\footnotetext{
${ }^{1}$ Friedrich Miescher Institut, Basel CH-4058, Switzerland. Correspondence and requests for materials should be addressed to P.C. (email: caroni@fmi.ch)
} 